\title{
Air pollution and mortality in Valencia, Spain: a study using the APHEA methodology
}

\author{
Ferran Ballester, Dolors Corella, Santiago Pérez-Hoyos, Anna Hervás
}

\begin{abstract}
Study objective - To assess the short term relationship between daily air pollution indicators (black smoke and sulphur dioxide $\left(\mathrm{SO}_{2}\right)$ ) and mortality in Valencia.

Design - This was an ecological study using time series data with application of Poisson regression. Daily variations in four selected outcome variables (total mortality, mortality in those over 70 years of age, and cardiovascular and respiratory mortality) were considered in relation to daily variations in air pollution levels for the period 1991-93.

Setting - The city of Valencia, Spain.
\end{abstract}

Main results - The mean daily mortality was 17.5 , and the average daily levels of air pollutants from the three monitoring stations included in the study were, $67.7 \mu \mathrm{g} / \mathrm{m}^{3}$ for black smoke, and $39.9 \mu \mathrm{gl}$ $\mathrm{m}^{3}$ for $\mathrm{SO}_{2}$. A significant positive association between black smoke and three of the four outcomes in the study was found. The estimated relative risk (RR) of dying corresponding to a $10 \mu \mathrm{g} / \mathrm{m}^{3}$ increase in mean daily black smoke over the whole period was 1.009 (95\% confidence interval (95\% CI): 1.003, 1.015). For mortality in the group aged more than 70 years and for cardiovascular mortality, the RRs were 1.008 (95\% CI: $1.001,1.016)$ and 1.012 (95\% CI: $1.003,1.022)$ respectively. The association with $\mathrm{SO}_{2}$ was less clear: it was only evident during the warm season. The estimated RRs in this case were $1.007(95 \%$ CI: $0.999,1.015)$ for total mortality, 1.009 (95\% CI: $1.00,1.21)$ for total mortality in those older than 70, and 1.012 (95\% CI: $0.995,1.026)$ for cardiovascular deaths. No significant association was found between mortality from respiratory diseases and either of the two pollutants.

Conclusions - A positive relationship between air pollution and mortality was found in the short term, as has been shown in an important number of studies carried out elsewhere. Although the current levels of particulate air pollution in Valencia are not very high, they could have an effect on the number of premature deaths. Despite the fact that the association is weak, it is important at the public health level both because of the numbers of population exposed and the possibility of establishing control measures.

(f Epidemiol Community Health 1996;50:527-533)
In recent years, a growing number of epidemiological studies have suggested that increases in air pollution could cause increases in daily mortality, even where levels of pollutants are below those considered as safe. Most published reports of this have come from investigations carried out in the USA, which show that particulate matter is the pollutant which exhibits this relationship most clearly. ${ }^{12345}$ In Europe, a series of investigations has also been carried out but with more diverse results in terms of the pollutant with the strongest association (in many cases it has been $\mathrm{SO}_{2}$ and not particulate matter), and because of difficulties in comparing results obtained from studies in which different methods have been used to determine the concentrations of pollutants or where different methodology may have been used for the epidemiological analysis. 6789

In Valencia, air pollution is not currently regarded as a serious problem ${ }^{10}$ and there are no previous published reports on air pollution and mortality. Towards the end of 1993 we began a study which aimed to examine whether there was an association between pollution and mortality in Valencia as elsewhere. We undertook this study using the APHEA protocol which has been described previously. ${ }^{11}$ This European project began in 1992 and has developed an extensive and valuable database from 10 countries with different social, climatic, and environmental conditions. We present here the results of our study in Valencia using epidemiological analysis of the time series data from the APHEA study.

\section{Methods}

DESIGN

This was an ecological study using time series data to which Poisson regression was applied. Daily variations in several selected causes of death were related with daily variations in air pollution levels for the period 1991-93.

\section{STUDY AREA}

The study was carried out in the city of Valencia (Spain). Its population, according to the census, of 1991, is over 750000 . Valencia is situated on the shores of the Mediterranean. There are few green spaces within the boundaries, although several zones dedicated to agriculture are retained. The climate is that known as mesothermal (temperate), with mild, humid winters and warm, hot summers. Given the low level of rainfall it is classified as arid- 
semiarid. ${ }^{12}$ Its topography is completely flat, with infrequent temperature inversion phenomena. The wind predominantly blows from the sea (to the east), thus alleviating the intense heat in the summer months.

\section{MORTALITY DATA}

The daily number of deaths in Valencia was obtained from the Valencian community's mortality register. The group to be studied was restricted to the city's residents only. There have been many published reports on the completeness of the register and the quality of patient diagnosis and the cause of death data that appear on the certificate used to create the statistics. ${ }^{1314}$ These show that the register is reliable. To be more specific, a high level of accuracy of the results obtained for all cause mortality and for mortality from tumours and diseases of the circulatory system has been shown, but in the case of diseases of the respiratory system the results have been less satisfactory. ${ }^{15}$ The groups considered in this study were: total mortality, total mortality for subjects over 70 years of age, and mortality from diseases of the circulatory system (ICD9 codes 390 to 459 ) and the respiratory system (ICD9 codes 460 to 519). In our study we tried very hard to guarantee the quality of our data, and in a second phase of the programme we recovered 44 deaths that had been registered late.

\section{AIR POLLUTION DATA}

The information on the values of the levels of air pollutants comes from the Valencian community's Air Pollution Monitoring Network. This network also has at its disposal the Reference Laboratory for Air Pollution which systematically intercalibrates the different laboratories that produce data for the network. The basic parameters with which this network deals are sulphur dioxide $\left(\mathrm{SO}_{2}\right)$ and the particles in suspension (black smoke). The indicator that is obtained is the accumulated value over 24 hours. The analytical methods and the characteristics of the monitoring sets were established in the context of the European Union. ${ }^{1617} \mathrm{SO}_{2}$ is detected using the "thorine" technique (spectrophotometric method). With regard to the suspended particles, the method used is that of "normalised smoke" (black smoke). The blackening is measured by reflectometry. Using this method, it is principally the breathable particles that are captured (typically those with an aerodynamic diameter of less than $4.5 \mu \mathrm{m}$ ), from there on the number of particles captured decreases, with the proportion of particles with a diameter greater than 7-9 $\mu \mathrm{m}$ being much lower.

In the city of Valencia, the network currently has 13 fixed monitoring sets for measuring the levels of particles and $\mathrm{SO}_{2}$. Of these 13 stations, five have corresponded since the end of 1990 to the type known as "weekly", which allows the collection of sequenced samples for up to eight days at a time. The other eight sets are of the "daily" type in which the change of filter and capture solution has to be carried out manually by an operative on each occasion. As a result of this the number of weekly determinations in these eight stations is limited to four. Because of this, we have limited the study to the years 1991-93, and used data from the "weekly" monitoring stations.

Air pollution data from two if these five stations were excluded because one of them showed around $35 \%$ missing values for the study period and the other was in a location that was considered as inadequate. As a result, the values used to measure air pollution are those obtained from an average of the three remaining stations. The percentage of days with missing values in any one of the three selected sets varied between $6 \%$ and $13 \%$ for black smoke, and between $8 \%$ and $13 \%$ for $\mathrm{SO}_{2}$. The sets are located within the urban area of Valencia with a medium to intense level of vehicular traffic. Motor vehicles are considered one of the principal sources of pollutant emission given that there is not a great deal of heavy industry in the city and people do not often burn fuels for heating because of the mild climate during the winter.

\section{METEOROLOGICAL DATA}

The mean daily temperature and daily relative humidity figures were obtained from the $\mathrm{Na}$ tional Institute of Meteorology at the city's weather station in the Meteorological Centre of Valencia. This location was considered more representative than another centre near the city, situated at the airport given that in various studies the effects of the thermal island, which is produced in the city of Valencia, showed up. ${ }^{1819}$ This effect consists of the modification of the temperature fields produced by large urban agglomerations. In the city of Valencia, its magnitude varies from almost nil values when there are strong winds to over $6^{\circ} \mathrm{C}$ in anticyclonic situations with clear skies and slight winds.

\section{INFLUENZA}

In Spain there is a monitoring procedure for notifiable diseases that involves every doctor. The quality of this register has also been evaluated and shows a good level of coverage in the Valencia region. ${ }^{20}$ The numbers of cases of influenza registered weekly was obtained from the epidemiological services of the city of Valencia, and this total was divided by seven to obtain an approximation of the daily incidence of influenza. The use of the variable with continuous data was preferred to the construction of a variable dummy with only two possible values, epidemic and non-epidemic periods.

\section{ANALYSIS}

The analysis procedure followed to assess the relationship between mortality and pollutants is based on that of the APHEA project and is explained in more detail elsewhere. ${ }^{2122}$ This ensures the comparability of the results with 
those obtained in the other cities of the study. In our case this approach consisted of the following.

\section{Identification of the core models}

Identifying a core model, by means of the least squares regression method, was undertaken for each of the causes of mortality studied. For control of confounding the following factors were taken into account:

(1) Seasonality. For this the sinusoidal terms up to the 6 th order were tested. The criteria to decide sin and cos terms to be included in the model were, either, when they jointly improved the model ( $\mathrm{F}$ of change on introducing them jointly $<0.10$ ), or when one of them (sin or cos of the same order) remained significant $(\mathrm{p}<0.05)$ with the final core model.

(2) Temperature and humidity. Both were introduced into the linear form model, this being the form with the best adjustment. The lags were tested jointly for both variables up to two days before, selecting the set according to its adjustment.

(3) Long term trends. A trend variable was introduced for the whole period and a dummy variable was tested for each year. An additional seasonality control was carried out preserving the year-indicating variables within the models and introducing the interactions of these variables with trigonometric functions.

(4) Day of the week and holiday. Six dummy variables were tested for the days of the week, taking Monday as the base. These variables were maintained in the model on the basis of statistical significance (F-test for all six variables $<0.10$ ). The "holiday" variable was introduced separately into the model, with the same criteria for maintaining it there.

(5) Influenza incidence, in continuous form, as mentioned above. Its lags from 1 to 15 were tested.

\section{Selection of the air pollution variables}

Each pollutant was studied separately in order to avoid multicollinearity. The residuals of mortality and of each pollutant after applying the core model were plotted to decide if the pollution variables were transformed. Also tested in the model was the log-transformation of each pollutant, but as the linear form fitted the model better, it was the one finally chosen.

Subsequently, the lags of each pollutant were tested (up to the 5th) choosing in each case the current lag with best adjustment. This was performed in similar fashion with the averages of 2, 3, and 4 days, including lag 0 in all cases.

\section{Final Poisson regression models}

With the models defined in the previous stage the final models were built using the Poisson regression. Four final models were obtained for each pollutant. In the first two cases the variable used as a pollution indicator was either the current lag (one day measurement) or the cumulative (average) selected in the previous stage. In the other two cases the models were the same as in the previous case, including additionally a dummy variable for the season ( 1 if month = from November to April "cold season", and 0 if month = from May to October "warm season") in the model, plus an interaction term for the air pollutant and the season variable in order to assess modification effect in relation to season.

When the seasonality terms were introduced, qualitative changes were seen in some of the groups studied, and we proceeded to carry out an analysis stratified by season. In all cases the possible autocorrelation of mortality residues was checked, along with the significance of the parameters up to the second order.

Finally, the interaction between black smoke and $\mathrm{SO}_{2}$ was investigated. A dummy variable was created for black smoke (cut off point for "low" versus "high" $-100 \mu \mathrm{g} / \mathrm{m}^{3}$ ) and the interaction term between the said variable and $\mathrm{SO}_{2}$ was introduced into the $\mathrm{SO}_{2}$ model with no statistical significance emerging. A dummy variable was not created for $\mathrm{SO}_{2}$, since for the Valencian data there was only one day during which the cut off point established in the procedures of the APHEA project $\left(100 \mu \mathrm{g} / \mathrm{m}^{3}\right)$ was exceeded.

\section{Results}

DESCRIPTIVE RESULTS

Table 1 summarises the average daily mortality values, the levels of black smoke and $\mathrm{SO}_{2}$, as well as the average temperature and relative humidity in relation to the whole period and the two seasons in the study. In Valencia there

Table 1 Daily mortality in the groups studied, air pollutant values $\left(\mu \mathrm{g} / \mathrm{m}^{3}\right)$, and meteorological data, Valencia, Spain 1991-93

\begin{tabular}{|c|c|c|c|c|c|c|c|c|c|}
\hline & \multicolumn{5}{|c|}{ All year } & \multicolumn{2}{|c|}{ Warm months } & \multicolumn{2}{|c|}{ Cold months } \\
\hline & Mean & $S D$ & Min & $\operatorname{Max}$ & No & Mean & $S D$ & Mean & $S D$ \\
\hline Total mortality & 17.49 & 5.03 & 5 & 36 & 1096 & 15.68 & 4.37 & 19.33 & 5.00 \\
\hline Total mortality age $70+$ & 11.68 & 4.05 & 2 & 27 & 1096 & 10.24 & 3.36 & 13.14 & 4.17 \\
\hline Respiratory mortality & 1.59 & 1.36 & 0 & 7 & 1096 & 1.25 & 1.15 & 1.93 & 1.48 \\
\hline Cardiovascular mortality & 6.93 & 3.06 & 0 & 19 & 1096 & 5.91 & 2.69 & 7.97 & 3.07 \\
\hline Black smoke $(24-\mathrm{h})$ & 67.68 & 28.83 & 5.00 & 226.00 & 1096 & 58.07 & 20.79 & 77.43 & 32.37 \\
\hline $\mathrm{SO}_{2}(24-\mathrm{h})$ & 39.94 & 15.38 & 7.00 & 105.50 & 1088 & 39.35 & 16.28 & 40.54 & 14.39 \\
\hline Mean temperature $\left({ }^{\circ} \mathrm{C}\right)$ & 17.51 & 5.72 & 5.00 & 30.30 & 1096 & 22.05 & 3.86 & 12.91 & 2.95 \\
\hline Humidity (\%) & 67.65 & 13.15 & 32.46 & 95.41 & 1096 & 66.48 & 12.23 & 67.65 & 14.02 \\
\hline
\end{tabular}

Warm months = May, June, July, August, September, October. Cold months = November, December, January, February, March, April. 


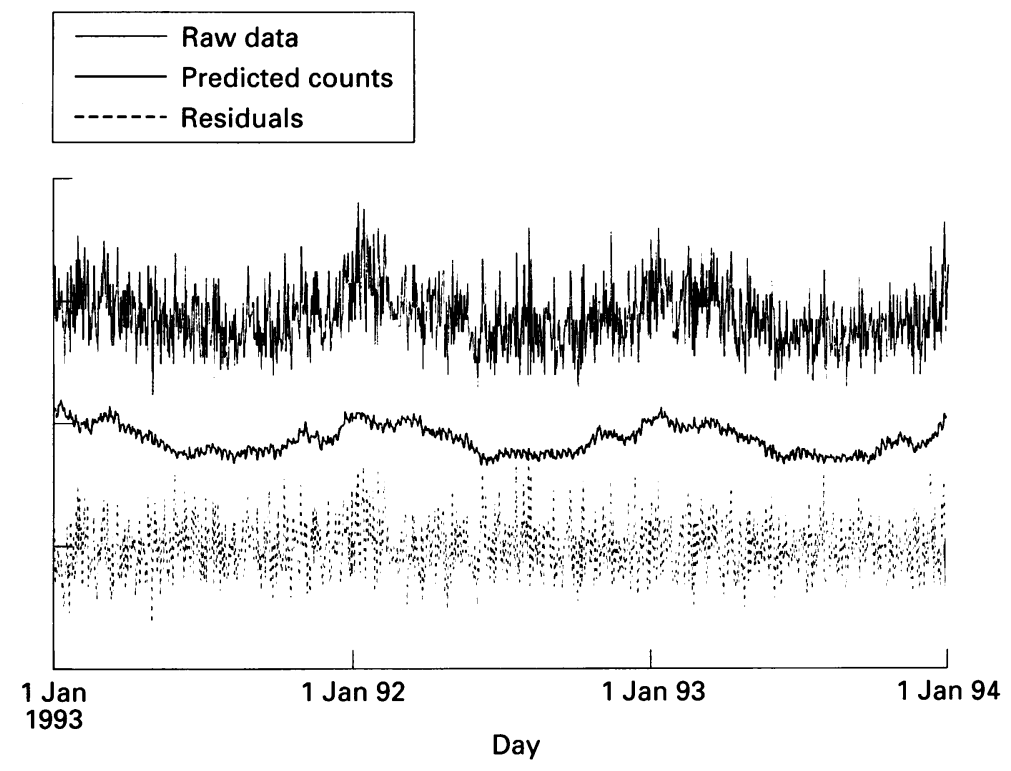

Figure 1 Time series of daily values of raw data, predicted counts, and residuals of the core model for total mortality.

\section{REGRESSION RESULTS}

Figure 1 shows the daily values of the raw data, the predicted values, and the residuals of the core model for total mortality, obtained by least square regression before including the pollutant variables. With the construction of this model the intention was to deseasonalise the mortality series. In the case of total mortality, the core model accounts for more than $20 \%$ of the variability of the daily mortality $\left(R^{2}=0.22\right)$.

The results of final Poisson models for pollutants are shown in table 2 , with an indication of the variables included in each case. None of the dummy variables for the years resulted in statistical significance, as a result of which they were not retained in the model. Likewise, the dummy variables were not included in any other model because they did not exhibit the required level of adjustment in the case of either "movable feasts" or (despite all cases being examined) the autoregressive terms.

Following the APHEA protocol the pollution indicator with the best adjustment is shown for each model. In general, the associations between mortality and air pollution were more significant using one day measurements than the average of several days, except in the case of subjects over 70 years of age, among whom a greater regression coefficient was obtained when taking into consideration the mean values for both the date of death and the three days prior to it (regression coefficient 0.00114, standard error 0.00052). The linear form was chosen for the pollutants because it showed a better adjustment than its logarithmic transformation.

On studying the whole series, before including the interaction term, a significant association can be found between daily mortality and the concentrations of black smoke but not for $\mathrm{SO}_{2}$. This association is seen more specifically with mortality from all causes, mortality in those older than 70 years, and mortality from cardiovascular diseases. No association was found, however, between black smoke and mortality from respiratory diseases.

With regard to black smoke, the introduction of its interaction term with season did not show substantial seasonal behaviour. In figure 2 the relative risks (RR) corresponding to each cause for the whole year are shown. In the case of less variation - approximately $20 \%$ more.

Table 2 Summary results of Poisson regression models for air pollutants, Valencia, Spain 1991-93

\begin{tabular}{lllllll}
\hline Pollutant $\left(\mu \mathrm{g} / \mathrm{m}^{3}\right)$ & Cause of death & $\begin{array}{l}\text { Lag* } \\
(d)\end{array}$ & $\begin{array}{l}\text { Coefficient } \\
\text { Beta }\end{array}$ & $S D$ & $\begin{array}{l}R R \\
\left(\text { per 1 } \mu \mathrm{g} / \mathrm{m}^{3}\right)\end{array}$ & $\begin{array}{l}95 \% \\
\text { confidence interval }\end{array}$ \\
\hline Black smoke (24-h) & Total mortality & 3 & 0.0008951 & 0.000310 & 1.0009 & $1.0003,1.0015$ \\
& Total age 70+y & 0 & 0.0008302 & 0.000380 & 1.0008 & $1.0001,1.0016$ \\
& Respiratory mortality & 1 & -0.0007272 & 0.000898 & 0.9993 & $0.9975,1.0010$ \\
$\mathrm{SO}_{2}$ (24-h) & Cardiovascular mortality & 4 & 0.0012320 & 0.000481 & 1.0012 & $1.0003,1.0022$ \\
& Total mortality & 2 & 0.0006906 & 0.000425 & 1.0007 & $0.9999,1.0015$ \\
& Total age 70+y & 2 & 0.0008731 & 0.000619 & 1.0009 & $0.9997,1.0021$ \\
& Respiratory mortality & 2 & -0.0028560 & 0.001750 & 0.9971 & $0.9937,1.0006$ \\
& Cardiovascular mortality & 2 & 0.0009878 & 0.000783 & 1.0012 & $0.9995,1.0025$ \\
\hline
\end{tabular}

${ }^{*} \operatorname{Lag}(x)$ indicates the lag $(x)$ of air pollutant with the best fit.

Model for total mortality: $\sin 1, \cos 1, \sin 4, \cos 4, \sin 5, \cos 5, \sin 6, \cos 6$, trend, temperature (lag 1$)$, humidity (lag 1 ), days of the week.

Model for total mortality in older than 70 years: $\sin 1, \cos 1, \sin 4, \cos 4, \sin 5, \cos 5, \sin 6, \cos 6$, trend, temperature (lag 1 ), humidity (lag 1), days of the week.

Model for respiratory mortality: $\sin 1, \cos 1, \sin 2, \cos 2, \sin 3, \cos 3$, influenza incidence, temperature $(\operatorname{lag} 2)$, humidity (lag 2$)$ Model for cardiovascular mortality: $\sin 1, \cos 1, \sin 3, \cos 3, \sin 4, \cos 4$, temperature, humidity, days of the week. 


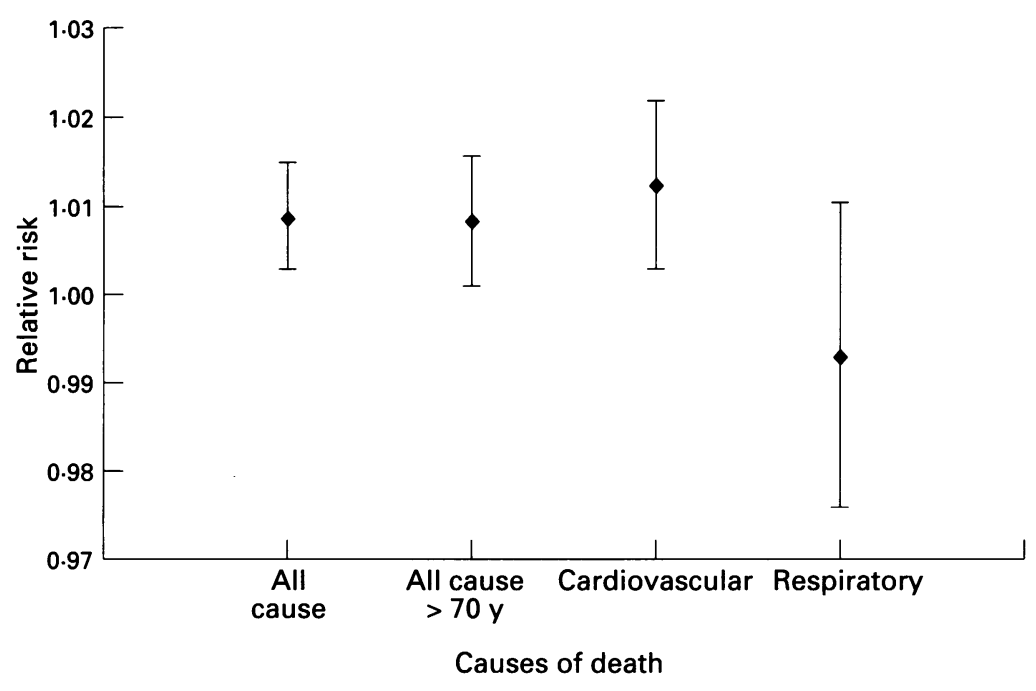

Figure 2 Relative risks (95\% confidence intervals) of death associated with an increase in the concentration of black smoke of $10 \mu \mathrm{g} / \mathrm{m}^{3}$.

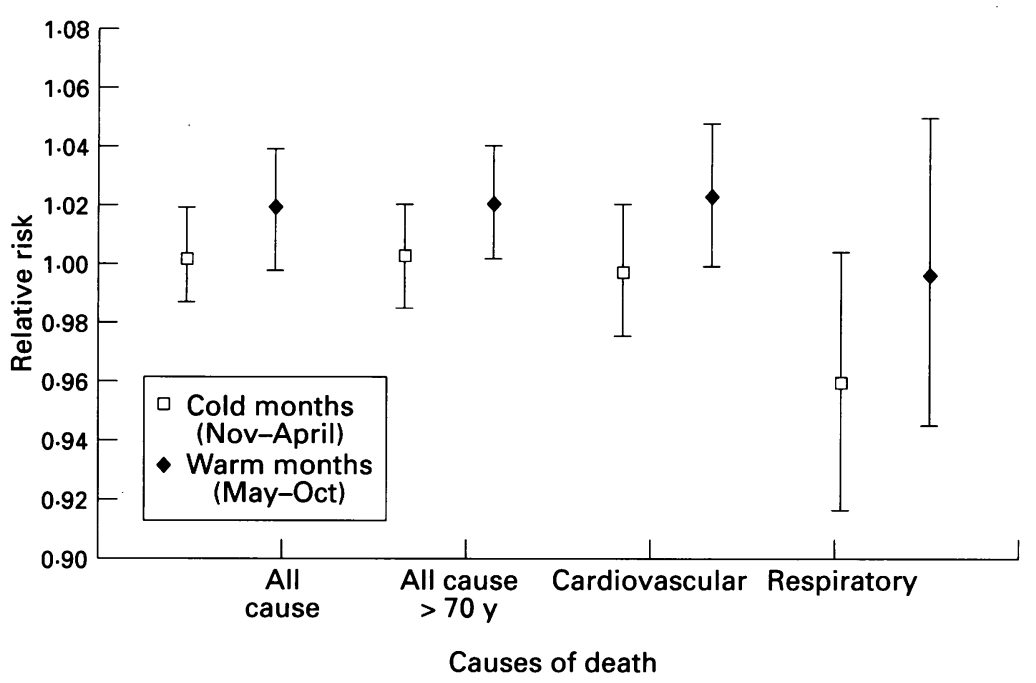

Figure 3 Seasonal variations in the relative risks (95\% confidence intervals) of death associated with an increase in the concentration of sulphur dioxide of $10 \mu \mathrm{g} / \mathrm{m}^{3}$.

$\mathrm{SO}_{2}$, however, on introduction of the variable season and its interaction there were changes in some of the coefficients of interest as a result of which we proceeded to carry out a stratified analysis. In this case, seasonal behaviour was evident. As can be observed in figure 3, the RR of dying associated with daily concentrations of $\mathrm{SO}_{2}$ are greater during the warm months than during the cold months in all four groups. Furthermore, for total mortality in those older than 70 years and (to a large extent) for the cardiovascular causes of death, this association is significant for the warm season. The additional control for seasonality by means of interacting year-designating variables with trigonometric functions did not alter the manifest association. The inclusion of the interaction term between the two pollutants did not indicate a possible synergistic effect.

\section{Discussion}

Compared with the other cities that participate in the APHEA study (descriptive results have been reported elsewhere ${ }^{11}$ ), the Valencian data are intermediate with regard to pollution levels, lower for $\mathrm{SO}_{2}$ than for black smoke, and, in terms of meteorology, Valencia has one of the mildest winters and the hottest summers, comparable to Athens. With regard to seasonality (data not shown here), mortality shows a pattern similar to the other Mediterranean cities and is more accentuated than in the cities to the north and centre of Europe.

One of the main findings of this study is the discovery of a significant association between air pollution and mortality indicators in the city of Valencia. The methodology employed has been similar to that of the other participants in the APHEA project, a fact which permits the comparison of our results with those obtained from the data sets of other cities in the study. The aim of this approach to take into adequate account the possible confounding factors, as well as controlling the autocorrelation. The existence of seasonal patterns in relation to the study and the possible interaction between the pollutants were also investigated.

When evaluating the results of this type of study, it has to be remembered that the variability of the parameters obtained in the adjusted regression models depends on the size of the population and the duration of the study. With regard to the first point, the population of Valencia is not large when compared with some of the cities in the APHEA study, as a result of which the estimates obtained could be a little unstable, especially when they are studied in relation to causes. With regard to the second point, the availability of pollution data restricted the study period to three years, which hinders attainment of statistical significance.

This choice presents certain advantages, such as having up to date information which allows a more accurate estimation of the impact of pollution on mortality with the present characteristics regarding levels and the composition of the pollutants. On the other hand, however, the time periods studied are not long enough to hope that the variation in the age structure and other population characteristics that are important factors in the variation of the occurrence of death (smoking habit, employment, exposure in the home, diet, exercise etc) will change substantially. ${ }^{23}$ As in all ecological studies, the results of the study should be viewed with caution when making causal imputations.

An important, widely known problem in this type of study is the high level of misclassification in terms of evaluating exposure. The whole population of the city has the same level of exposure assigned, independent of the area in which they carry out their daily lives and without taking into account the time they spend inside buildings. In addition, classification of exposure depends on the quality of the atmospheric information. The pollutant data depend largely on the situation of the monitoring stations. The need to improve the quality of information required to carry out this type of study should be highlighted, especially when referring to levels of exposure. We believe that in both the field of epidemiology as well as in that of the professionals involved in the 
monitoring of air pollution, an effort should be made to collaborate closely in this type of study.

This is the first study of the short term effects of air pollution on mortality carried out in Valencia. The results obtained are consistent with those from other European cities. They are, however, more similar to those obtained in American studies, where the association between air pollution and mortality is clearer for particulate matter than for $\mathrm{SO}_{2}$. Over the past few years, there have been various reviews of the topic. ${ }^{24-26}$ In these, the authors resolve the problems of comparability of results between the different measures of exposure determination by using criteria based on chemical and morphological knowledge of the particles which allow the transformation of the values obtained into a measurement method that corresponds to the one that would have been obtained using a different measurement procedure. In this sense it is considered that, among other criteria, the value obtained for black smoke levels using the reference measuring method used within the European Union, ${ }^{1617}$ should approximate to that obtained by the measurement method of the Environmental Protection Agency (EPA) of the USA (for measuring particles smaller than $10 \mathrm{~mm}) .{ }^{27}$ Both measures would be approximately equivalent, according to the authors, to $55-60 \%$ of the total suspended particles (TSP), allowing an approximation of the relative magnitude of the effects to be made. In this way, the estimated effect in the three mentioned revisions ranges between a $0.6 \%$ and $1 \%$ increase in daily mortality for an increase of $10 \mathrm{mg} / \mathrm{m}^{3}$ in suspended particles, expressed in $\mathbf{P M}_{10}$. In our case, the effect estimate of the change in daily mortality from all causes for each $10 \mathrm{mg} / \mathrm{m}^{3}$ increase in black smoke concentration was of $0.9 \%$ (95\% confidence interval, $0.3,1.5 \%$ ), a result that is very similar to those mentioned above. For mortality from specific causes, our results are in line with those obtained in other studies, ${ }^{26}$ with a higher estimated risk for cardiovascular mortality compared with all cause mortality, but no significant association for respiratory mortality. This fact could be due to various reasons, but in our opinion it is principally due to the low number of deaths from respiratory diseases in Valencia (approximately 1.5 deaths per average day). However, as we mentioned in the methods section, studies carried out in Valencia ${ }^{15}$ have shown that in the case of deaths from respiratory causes the reliability of the diagnosis obtained from the medical certificate is relatively low (sensitivity of $\mathbf{5 5 \% \text { ). }}$

Occasionally, the results of these studies have been put in, doubt by the lack of a physiopathological mechanism that would be biologically plausible, especially in the case of the association with mortality from cardiovascular diseases. ${ }^{28}$ Faced with these objections it has been argued that as well as the misclassification that can exist (eg, deaths from bronchitis and bronchiolitis being classified as caused by cardiovascular diseases), some acute respiratory diseases can cause a pulmonary oedema. $^{29}$ In addition, some authors have suggested that the episodes of air pollution constitute an additional environmental stress factor that can cause the death of compromised patients. Several physiological hypotheses have been formulated on the way in which the particles act on the human body. In a recent report, ${ }^{30}$ it was suggested that the explanation for this association is that the particulate matter in cities might contain a very high concentration of ultra fine particles. Even though their concentration might not be not very high gravimetrically, these particles could provoke alveolar inflammation that would liberate mediators capable, in susceptible individuals, of causing an exacerbation of respiratory problems and increasing the coagulability of the blood. This might explain the increase in the number of deaths from cardiovascular problems as a result of air pollution. A similar hypothesis has been presented in which the ultra fine particles $(<50 \mathrm{~nm})$ present in the urban atmosphere have a toxic reactive capability. $^{31}$

$\mathrm{SO}_{2}$ presents less clear results in our study. It shows a seasonal pattern with a mortality association that is significant only during warm months. This fact contrasts with the results obtained in other European studies, where it emerges as the pollutant with the clearest association with mortality. ${ }^{89}$ In a study carried out in The Netherlands, ${ }^{32}$ no statistically significant association was found either, although in this particular case the levels of $\mathrm{SO}_{2}$ were low (average $18 \mathrm{mg} / \mathrm{m}^{3}$ ), and in addition, the same measure of exposure (determined by six monitoring stations spread nationwide) was applied to the Dutch population as a whole. The levels of $\mathrm{SO}_{2}$ in Valencia during the study were also low or moderate, partly explaining the nonsignificant association when the year is analysed as a whole.

The greater effect of $\mathrm{SO}_{2}$ on mortality during the warmer months could be a result of its greater detectibility at a time when there are fewer competing risk factors (especially respiratory infections). Furthermore, as there are fewer deaths during the warmer months, any variations have a greater impact on the results. However, it has been suggested that the greatest effects of pollution during hot months could be a result of higher individual exposure based on modified activity patterns. ${ }^{33}$ This includes the fact that people spend more time outdoors and windows are left open for longer, so the indoor concentrations are closer to those found outdoors.

In conclusion, the association found shows a positive relationship between air pollution and mortality in the short term, as has been witnessed in a considerable number of investigations carried out elsewhere. These findings suggest that although the present levels of particulate air pollution in the city of Valencia are not being very high, they could have an effect on the number of premature deaths. The association is a weak one, but it is nevertheless important at a public health level both due to the numbers of population exposed and to the possibility of establishing control measures. 
1 Schwartz J, Dockery DW. Particulate air pollution and daily mortality in Steubenville, Ohio. Am f Epidemiol 1992;135: $12-9$

2 Schwartz J. Air pollution and daily mortality in Birmingham, Alabama. Am f Epidemiol 1993;137:1136-47.

3 Pope CA III, Schwartz J, Ramsom MR. Daily mortality and $\mathrm{PM}_{10}$ pollution in Utah Valley. Arch Environ Health 1992 47:211-7.

4 Schwartz J. Particulate air pollution and daily mortality in Detroit. Envirn Res 1991;56(2):204-13.

5 Schwartz J. Total suspended particulate matter and daily mortality in Cincinnati, Ohio. Environ Health Perspect 1994;102(2): 186-9.

6 Loewenstein JC, Bourdel MC, Bertin M. Influence de la pollution atmosphérique ( $\mathrm{SO}_{2}$ - poussières) et des conditions metéorologiques sur la mortalité à Paris entre 1969 et 1976. Rev Epidemiol Santé Publique 1983;31: $143-61$

7 Hatzakis A, Katsouyanni K, Kalandidi A, Day N, Trichopoulos D. Short-term effects of air pollution on mortality in Athens. Int $\mathcal{f}$ Epidemiol 1986;15:397-9.

8 Derrienic F, Richardson S, Mollie A, Lellouch J. Shortterm effects of sulphur dioxide pollution on mortality in two French cities. Int $\mathcal{F}$ Epidemiol 1989;18:186-97.

9 Toulomi G, Pocock SJ, Katsouyanni K, Trichopoulos D. Short-term rffects of air pollution on daily mortality in Athens: a time series analysis. Int $\mathcal{f}$ Epidemiol 1994;23: Athens:

10 Laboratorio Municipal. Delegación de Salud y Consumo. Ayuntamiento de Valencia. Contaminación atmosférica en
la ciudad de Valencia. Marzo 1992. In: Medio ambiente y la ciudad de Valencia. Marzo 1992. In: Medio ambien
salud. Valencia: Fundación Cañada Blanch, 1993.

11 Katsouyanni K, Zmirou D, Spix C, et al. Short-term effects of air pollution on health: a European approach using epidemiologic time series data. Eur Respir f 1995;8:1030-8.

12 Roldán A. Notas para una climatologia de Valencia. Instituto Nacional de Meteorologia. Publicación Serie K no 6. Madrid: Instituto Nacional de Meteorologia, 1985.

13 Benavides FG, Bolumar F, Peris R. Quality of death certificates in Valencia, Spain. Am 7 Public Health 1989:79: $1352-4$

14 Benavides FG, Segura A, Godoy C. Estadisticas de mortalidad en España: pequeños problemas, grandes perspectivas. Revis Salud Pública 1991;2:43-66.

15 Benavides FG. Fiabilidad de las estadisticas de mortalidad. Generalitat Valenciana. Conselleria de Sanitat i Consum.
Monografies Sanitàries Serie A, num 2,1986. Valencia: Monografies Sanitàries Serie A, num 2, 1986. Valencia: Conselleria de Sanitat i Consum, 1986.

16 Diario Oficial de las Comunidades Europeas. Directiva del Consejo de 15 de julio de 1980 , relativa a los valores limite y a los valores guia de calidad atmosférica para e anhidrido sulfuroso y las particulas en suspensión ( 80 779/CEE).

17 Diario Oficial de las Comunidades Europeas. Directiva del Consejo de 21 de junio de 1989 por la que se modifica la Directiva 80/779/CEE (89/427/CEE).
18 Caselles V, López Garcia MJ, Meliá J, Pérez Cueva AJ. El efecto de la isla térmica de la ciudad de Valencia obtenido a partir de transectos e imágenes NOAAAVHRR. Libro de comunicaciones de la III Reunión Cientifica del Grupo de Trabajo en Teledetección. Madrid, Octubre 1989. Madrid: Asociación Española de Termodinámica, 1989:259-69.

19 Pérez Cueva AJ. Brisas e isla térmica urbana en Valencia. In: Universitat de València. Aportaciones en homenaje al profesor Luis Miguel Albentosa. Valencia: Universitat de València, 1992:193-203.

20 Tello O, Cano R, Hernández G. Situación actual y análisis de la vigilancia epidemiológica en España. In: Vigilancia Epidemiologica: !' hacia que modelo vamos?.
tro Nacional de Epidemiologia, 1992:91-9.

21 Schwartz J, Spix C, Touloumi G et al. Methodological issues in studies of air pollution and daily counts of deaths or hospital admissions. F Epidemiol Community Health 1996; 50:S3-11.

22 Katsoyanni K, Schwartz J, Spix C et al. Short term effects of air pollution on health: a European approach usin epidemiologic time series data. The APHEA protocol $\mathscr{F}$ Epidemiol Community Health 1996;50:S12-18.

23 Holland WW, Bennett AE, Cameron IR, et al. Health effects of particulate pollution: reappraising the Evidence. $A m \mathcal{F}$ Epidemiol 1979;110:525-659.

24 Ostro B. The association of air pollution and mortality: examining the case for inference. Arch Environ Health 1993;48(5):336-42.

25 Schwartz J. Air pollution and daily mortality: a review and meta-analysis. Environ Res 1994;64(1):36-52.

26 Dockery DW, Pope CA III. Acute respiratory effects of particulate air pollution. Annu Rev Public Health 1994;15 107-32.

27 U.S. Environmental Protection Agency. Revisions to the national ambient air quality standards for the particulate matter: final rules. Washington: Federal Register 1987; 52(126):24634-69.

28 Waller RE, Swan AV. Invited commentary: particulate air pollution and daily mortality. Am $\mathcal{F}$ Epidemiol 1992;135: $20-2$.

29 Bates DV. Health indices of the adverse effects of air pollution: the question of coherence. Environ Res 1992;59. 336-49.

30 Seaton A, MacNee W, Donaldson K, Godden D. Particulate Air pollution and acute health effects. Lancet 1995;345: 176-8.

31 Oberdörster G. Airborne pollutants and acute health effects. Lancet 1995;345:799-800.

32 Mackenbach JP, Looman CW, Knust AE. Air pollution, lagged effects of temperature, and mortality: The Netherlands 1979-87. 7 Epidemiol Community Health 1993;47: 121-6.

33 Katsouyanni $\mathrm{K}$. Health effects of air pollution in southern Europe: are there interacting factors?. Environ Health Perspect 1995;103(Suppl2):23-7. 